\title{
A HISTÓRIA AMBIENTAL NO BRASIL E OS SEUS CLÁSSICOS
}

\author{
Por José Luiz de Andrade Franco*
}

PÁDUA, José Augusto Pádua. Um sopro de destruição: pensamento político e crítica ambiental no Brasil escravista (1786-1888). Rio de Janeiro: Jorge Zahar, 2002. $318 \mathrm{p}$.

Um sopro de destruição: pensamento político e crítica ambiental no Brasil escravista (1786-1888), livro de José Augusto Pádua, se insere na recente tradição da História Ambiental brasileira. A disciplina, surgida nos anos 1970, momento em que as preocupações de caráter ambiental se tornavam mais difundidas, começou a ser praticada, sobretudo, nos países de língua inglesa. Donald Worster, um dos mais ilustres historiadores ambientais norte-americanos, defende que ela nasceu de um objetivo moral e envolta em uma rede de compromissos políticos, tornando-se mais autônoma e acadêmica com a sofisticação de seus interesses e de seus objetos. Sua principal meta veio a ser a compreensão de como os seres humanos foram, através dos tempos, afetados pelo seu ambiente natural e, inversamente, como e com que resultados afetaram esse ambiente. Para Worster, são três os níveis em que a História Ambiental atua: o primeiro trata da natureza propriamente dita, como se organizou e funcionou no passado; o segundo aborda o domínio socioeconômico, na medida em que este interage com o ambiente; o terceiro enfoca as representações sociais relacionadas ao mundo natural. É fácil perceber que essas instâncias podem ser - e na verdade são - trabalhadas por outros cientistas sociais, como sociólogos, antropólogos e economistas.

No Brasil, o compromisso de se escrever uma História Ambiental é bastante recente, embora alguns de nossos mais afamados

* Doutor em História Social e das Idéias pela UnB; professor da UPIS (União Pioneira de Integração Social). 
historiadores e cientistas sociais tenham conferido destaque para determinados aspectos da relação entre homens e natureza em suas obras. Destacam-se autores como Capistrano de Abreu, Sérgio Buarque de Holanda, Caio Prado Jr., Gilberto Freire, Josué de Castro e Darcy Ribeiro. Entre aqueles que se propuseram a escrever no âmbito estrito da História Ambiental sobre o Brasil, algumas obras, mesmo que bastante recentes, já podem ser consideradas clássicas, pela sua qualidade e pelo fato de terem se tornado referências obrigatórias para quem quiser se aventurar por esse novo campo de estudos que combina o exame conjunto de processos naturais e sociais. Enquadramse, nesta categoria, os livros de Warren Dean, A luta pela borracha no Brasil: um estudo de história ecológica (Nobel, 1989) e A ferro e fogo: história e devastação da Mata Atlântica brasileira (Cia. das Letras, 1996); de José Augusto Drummond, Devastação e preservação ambiental: os parques nacionais do Estado do Rio de Janeiro (EDUFF, 1997); de Victor Leonardi, Entre árvores e esquecimentos: História social nos sertões do Brasil (UnB, Paralelo 15, 1996) e Os historiadores e os rios: natureza e ruína na Amazônia brasileira (UnB/Paralelo 15, 1999); e de Paulo Bertran, História da terra e do homem no Planalto Central: eco-história do Distrito Federal: do indígena ao colonizador (Solo, 1994).

José Augusto Pádua encontra-se entre os pioneiros da História Ambiental ou Ecológica no Brasil. Em seu artigo Natureza e projeto nacional: as origens da ecologia política no Brasil, publicado na coletânea, organizada por ele, Ecologia e política no Brasil (IUPERJ, Espaço e Tempo, 1987), foi, sem dúvida, um dos primeiros a aventar a possibilidade de um empreendimento deste tipo. As preocupações focalizadas pelo artigo, relacionadas ao tema da crítica à devastação da natureza no Brasil, de José Bonifácio a Euclides da Cunha e Alberto Torres, irão nortear a escrita de sua tese de doutoramento em Ciência Política, A degradação do berço esplêndido: um estudo sobre a tradição original da Ecologia Política brasileira 1786/1888, defendida no IUPERJ, em 1997, reflexão mais aprofundada e de escopo mais delimitado (o período estudado termina com a abolição da escravatura). Um sopro de destruição: pensamento político e crítica ambiental no Brasil escravista (1786-1888) retoma a problemática e os argumentos da tese de doutorado, mas não é simplesmente a sua reprodução. Há mais pesquisa, novos autores foram 
lidos e acrescentados, e o texto foi todo reestruturado, demonstrando amadurecimento e apuro das questões e análises propostas.

Trata-se de um livro que enfoca, sobretudo, o terceiro nível de análise da História Ambiental, aquele que segundo Worster se ocupa do tipo de interação mais intangível e humano, o aspecto das representações mentais e idéias, e que, portanto, exige do historiador atenção e esmero redobrado. Cerca de 150 textos produzidos entre 1786 e 1888, escritos por mais de 50 autores do período colonial e imperial brasileiros, são analisados por Pádua, revelando uma "tradição de pensamento", esquecida por muito tempo, relacionada à crítica dos padrões de exploração da natureza no Brasil.

Três questões de fundo perpassam o texto de José Augusto Pádua. A primeira diz respeito ao contraste entre o cientificismo progressista e o romantismo na origem da crítica ambiental brasileira. Pádua demonstra que, ao contrário do que ocorreu na Inglaterra, Alemanha e Estados Unidos, onde a crítica à destruição do mundo natural esteve associada ao ethos romântico, no Brasil, o romantismo, como movimento cultural, não chegou a organizar mobilizações de maior alcance neste sentido. Foram os intelectuais racionalistas, influenciados pela herança do Iluminismo, que se destacaram na elaboração de uma crítica ambiental brasileira, não por manifestarem um especial interesse pelo valor estético ou intrínseco da natureza, mas, sim, pelo seu valor político e instrumental para o progresso.

A segunda questão trata da afirmação da importância do estudo dos autores brasileiros dos séculos XVIII e XIX para o entendimento da gênese da sensibilidade ecológica no mundo moderno. Nesse ponto de sua análise, José Augusto Pádua estabelece uma conexão entre o seu estudo e os trabalhos inovadores de Richard Grove, sobretudo Green Imperialism, para mostrar como o surgimento de uma percepção da problemática ambiental não está relacionada apenas com as grandes transformações urbano-industriais ocorridas a partir do final do século XVIII na Europa, mas, também, com uma série de outros processos históricos que, em parte, lhe são anteriores. Entre estes são destacados o processo de expansão colonial européia e a consolidação da ciência como modo privilegiado de entendimento do mundo. Desse modo, a crítica ecológica moderna mostra-se tributária, em boa medida, da 
compreensão, por parte de cientistas e administradores, de que os processos econômicos adotados pelos colonizadores europeus em regiões como as ilhas Maurício, o Caribe, partes da Índia e da África, como no Brasil, estavam provocando uma degradação ambiental acelerada e evidente. Portanto, a evolução dos questionamentos da consciência ecológica nas regiões periféricas surge, não como um fator exógeno e tardio, mas como fruto de sua inserção no universo da modernidade.

A terceira questão de fundo se relaciona com o fato de que, embora os autores retratados por Pádua tenham escrito com o intuito pragmático de transformar a realidade do país, as suas propostas foram pouco implementadas durante todo o período estudado. Muitos dos intelectuais analisados desfrutavam de posição social e política destacada (e alguns até de cargos administrativos pertinentes às suas preocupações), tendo o debate e a crítica ambiental capturado, em alguns momentos, a imaginação do próprio Imperador Pedro II. A parcela da elite intelectual preocupada com a degradação do ambiente natural, no entanto, apesar de influente, esbarrava com limites muito claros quando se tratava de transformações que viessem a colocar em jogo a estrutura das relações de produção, matéria em que o próprio Estado encontrava dificuldades quando buscava impor reformas ou aperfeiçoamentos.

O conteúdo do livro se distribui em uma introdução, que constitui um excelente guia de viagem, delineando os principais problemas a serem abordados, e cinco capítulos. No primeiro capítulo são discutidas as fontes teóricas e os pontos de apoio institucional da primeira crítica ambiental brasileira: o papel da Universidade de Coimbra (onde estudaram centenas de brasileiros ou de portugueses residentes no Brasil) e da Academia de Ciências de Lisboa, as reflexões do cientista italiano (professor de Coimbra) Domenico Vandelli e do conselheiro Rodrigo de Sousa Coutinho, as obras de José Gregório de Moraes Navarro e de Baltasar da Silva Lisboa, as influências da História Natural - Lineu, Buffon e Humboldt - e da Fisiocracia. O segundo capítulo analisa um conjunto de textos produzidos no Brasil, entre 1799 e 1821, refletindo o choque entre o racionalismo dos intelectuais brasileiros retornados da Europa e a realidade brutal e destrutiva vigente na colônia. $\mathrm{O}$ terceiro capítulo 
enfoca a obra de José Bonifácio e o nexo por ele estabelecido entre devastação ambiental, atraso tecnológico e a escravidão. Os dois últimos capítulos tratam da crítica ambiental produzida no período posterior ao exílio de Bonifácio, destacando duas grandes vertentes, ambas inspiradas no exemplo do velho "patriarca": a primeira reunia intelectuais e homens públicos, muitos deles próximos ao Imperador, tais como Freire Alemão e Guilherme Capanema, preocupados em reverter o quadro da devastação da natureza pátria a partir de um reformismo tecnológico e administrativo, evitando tocar na questão da escravidão; a segunda vertente, representada, sobretudo, por autores como André Rebouças e Joaquim Nabuco, identificados com a causa do abolicionismo, reforçava a percepção bonifaciana de que a destruição imprevidente dos recursos naturais só poderia ser contida por meio de uma reestruturação geral da economia e da sociedade, incluindo a abolição da escravatura.

Em suas considerações finais, José Augusto Pádua chama a atenção para o fato de, na literatura por ele analisada, não haver obras, como Man and Nature, clássico da crítica ambiental norte-americana, publicado em 1864 por George Perkins Marsh, dedicadas especificamente ao tema ambiental, tendo a maioria dos textos dos autores brasileiros sido escrita como capítulos ou passagens de obras de escopo mais amplo, dedicadas a abordar os problemas sociais e econômicos do país. Essa característica, que poderia ser tomada como uma fraqueza teórica, é para o nosso autor, o que confere força e atualidade à tradição intelectual em questão. A intuição dos fundadores da crítica ambiental brasileira, que não eram "ambientalistas" no sentido moderno da palavra, mas pensadores preocupados com o destino do Brasil como um todo, foi de que os problemas ambientais relacionavam-se com estruturas abrangentes de cunho econômico, social e tecnológico. Portanto, "o estabelecimento de uma relação benéfica com o meio natural servia de componente básico para um propósito bem mais audacioso: modificar o rumo da sociedade brasileira, ou de algumas de suas expressões regionais, de forma a situá-la em um patamar superior de racionalidade e justiça" (p. 284). Essa perspectiva, segundo Pádua, se aproxima do tipo de abordagem que atribui a crise ambiental contemporânea não a falhas ou acidentes ocasionais dos sistemas produtivos, mas, sim, ao funcionamento cotidiano de padrões de produção e consumo 
insustentáveis, exigindo para a sua superação, mais do que medidas técnicas e setoriais, ações políticas voltadas para profundas transformações sociais, econômicas e culturais. Dessa forma, embora a tradição crítica da devastação da natureza produzida no Brasil dos séculos XVIII e XIX não deva ser vista como precursora do debate atual, as suas reflexões ganham relevância teórica e projeção histórica.

Ao resgatar a memória de uma tradição de pensamento que atribuía à relação do homem com o seu meio natural uma posição estratégica em suas reflexões, o livro de José Augusto Pádua representa uma possibilidade, para os que se interessam pelo debate em torno das questões ambientais, de ampliação da perspectiva histórica e da densidade analítica. Para aqueles que pretendem percorrer as trilhas da recente História Ambiental brasileira, esse Sopro de destruição é, sem dúvida, um poderoso alento, credenciando-se, desde já, como um clássico, e como tal, de imprescindível leitura. 